\title{
Expression and clinical significance of ATM and PUMA gene in patients with colorectal cancer
}

\author{
HUI XIONG and JIANGNAN ZHANG \\ Department of General Surgery, The First Affiliated Hospital of Nanchang University, \\ Nanchang, Jiangxi 330006, P.R. China
}

Received July 28, 2017; Accepted October 6, 2017

DOI: 10.3892/ol.2017.7181

\begin{abstract}
The expression of ataxia-telangiectasia mutated (ATM) and p53 upregulated modulator of apoptosis (PUMA) genes in patients with colorectal cancer were investigated, to explore the correlation between the expression of ATM and PUMA and tumor development, to evaluate the clinical significance of ATM and PUMA in the treatment of colorectal cancer. Quantitative real-time PCR was used to detect the expression of ATM and PUMA in tumor tissue and adjacent healthy tissue of 67 patients with colorectal cancer and in normal colorectal tissue of 33 patients with colorectal polyps at mRNA level. The expression level of ATM mRNA in colorectal cancer tissues was significantly higher than that in normal mucosa tissues and adjacent non-cancerous tissue $(\mathrm{P} \leq 0.05)$, while no significant differences in expression level of ATM mRNA were found between normal mucosa tissues and adjacent noncancerous tissue $(\mathrm{P}=0.07)$. There was a negative correlation between the expression of ATM mRNA and the degree of differentiation of colorectal cancer $(\mathrm{r}=-0.312, \mathrm{P}=0.013)$, while expression level of ATM mRNA was not significantly correlated with the age, sex, tumor invasion, lymph node metastasis or clinical stage $(\mathrm{P}>0.05)$. Expression levels of PUMA mRNA in colorectal cancer tissues, adjacent noncancerous tissue and normal tissues were $0.68 \pm 0.07,0.88 \pm 0.04$ and $1.76 \pm 0.06$, respectively. Expression level of PUMA mRNA in colorectal cancer tissues and adjacent noncancerous tissue was significantly lower than that in normal colorectal tissues $(\mathrm{P}<0.05)$. The results showed that ATM mRNA is expressed abnormally in colorectal cancer tissues. Expression of PUMA gene in colorectal carcinoma is downregulated, and is negatively correlated with the occurrence of cancer.
\end{abstract}

Correspondence to: Dr Hui Xiong, Department of General Surgery, The First Affiliated Hospital of Nanchang University, 17 Yongwaizheng Street, Nanchang, Jiangxi 330006, P.R. China E-mail: drxionghui17@163.com

Key words: colorectal cancer, ataxia-telangiectasia mutated, PUMA, mRNA expression

\section{Introduction}

With the improvement of people's living standards and changes in eating habits, morbidity and mortality rate of colorectal cancer has increased significantly in China in recent years. At present, surgical resection supplemented by chemotherapy and radiotherapy is the main treatment of colorectal cancer. Although short-term effect is satisfactory, the application of this treatment is still challenged by the adverse side effects, serious body injury, and high recurrence rate. In addition, treatment outcomes of patients with tumor metastasis are usually poor. Therefore, the development of safer and more effective treatment is always needed. The development of colorectal cancer is a long-term and complex process with various factors involved, such as diet, environmental factors, genetic factors, disease and other factors. The occurrence of colorectal cancer involves the activation of multiple protooncogenes and the inactivation of tumor suppressor genes (1), and mutations or deletions of tumor suppressor genes ATM and PUMA are major molecular biological changes in the development of colorectal cancer $(2,3)$. However, the expression and the clinical significance of ATM and PUMA in colorectal cancer have not been well studied. This study aimed to detect the expression of ATM and PUMA in colorectal cancer tissue by qRT-PCR, and to explore the roles of ATM and PUMA in the development and progression of colorectal cancer, so as to provide new insights for the treatment of colorectal cancer.

\section{Materials and methods}

General information. A total of 67 patients with colorectal cancer were selected in the First Affiliated Hospital of Nanchang University, from September 2015 to September 2016 to serve as observation group. The patients include 33 males and 34 females, and the age ranged from 45 to 79 years with an average age of $69.1 \pm 2.4$ years. Pathological staging: T1 in 15 cases, T2 in 19 cases, T3 in 23 cases and T4 in 10 cases; lymph node metastasis was found in 35 cases; low differentiation was found in 31 cases and high differentiation in 36 cases; mucosal and myometrial infiltration was found in 38 cases and outer layer infiltration in 29 cases; None of the patients received any treatment before the study. Inclusion criteria: patients with colorectal cancer diagnosed by histopathological 
examination; age $<80$ years; patients willing to participate in the biopsy for pathological examination of this study; patients with complete clinical, laboratory and imaging data; patients who signed informed consent. Exclusion criteria: patients with other types of primary malignant tumor; patients with congenital malformations; patients with acute infectious diseases; patients with severe liver and kidney dysfunction and coagulation dysfunction; patients failed to cooperate with researchers. At the same time, a total of 33 patients with colorectal polyps were selected as control group. The patients include 16 males and 17 females, and the age ranged from 50 to 78 years with an average age of $65.3 \pm 3.6$ years. All patients were diagnosed with colorectal polyps by pathological examination and all patients received high frequency electric coagulation trap exsection. No significant differences were found in general information between the two groups $(\mathrm{P}>0.05)$. The study was approved by the Ethics Committee of the First Affiliated Hospital of Nanchang University and informed consents were signed by the patients and/or guardians.

Methods. Tissue (50-100 mg) was ground in TRIzol $(1 \mathrm{ml})$ on ice. The suspension was transferred into $1.5 \mathrm{ml}$ centrifuge tubes and kept at room temperature for $5 \mathrm{~min}$ for complete dissociation to extract total RNA. Reverse transcription was then performed: 1) a DEPC-treated $200 \mu 1$ PCR tube was placed on ice, and total RNA, primer $(0.5 \mu \mathrm{g} / \mu \mathrm{l})$ and RNase-free water were added and mixed, followed by centrifugation for $30 \mathrm{sec}(1,409 \mathrm{x} \mathrm{g}) ; 2)$ denaturing at $70^{\circ} \mathrm{C}$ for $5 \mathrm{~min}$ in PCR machine, followed by cooling on ice; $5 \mathrm{X}$ RT Buffer, RNase inhibitor $(20 \mathrm{U} / \mu \mathrm{l})$ and $10 \mathrm{mM}$ dNTP Mix were added and centrifuged $(1,409 \mathrm{x} \mathrm{g})$ for $30 \mathrm{sec} ; 4)$ incubation at $25^{\circ} \mathrm{C}$ in PCR instrument for $5 \mathrm{~min}$, followed by cooling on ice; 5) $1 \mu \mathrm{l}(200 \mathrm{U} / \mu \mathrm{l})$ of M-MuLV reverse transcriptase and water was added to a final volume of $20 \mu \mathrm{l}$; 6) $25^{\circ} \mathrm{C}$ for $10 \mathrm{~min}, 42^{\circ} \mathrm{C}$ for $60 \mathrm{~min}$ and $70^{\circ} \mathrm{C}$ for $10 \mathrm{~min}$ in PCR instrument, followed by cooling on ice. PCR reaction was then performed: 1) 2X PCR Master Mix, cDNA, upstream and downstream primers, and sterilized and deionized water were added into a $200 \mu 1$ PCR tube, followed by centrifugation at $1,409 \mathrm{x}$ g for $30 \mathrm{sec}$; 2) PCR reaction was performed according to the operation instructions: $94^{\circ} \mathrm{C}$ for $5 \mathrm{~min}$, followed by $30-35$ cycles of $94^{\circ} \mathrm{C}$ for $30 \mathrm{sec}, 55-60^{\circ} \mathrm{C}$ for $45 \mathrm{sec}$, and $72^{\circ} \mathrm{C}$ for $45 \mathrm{sec}$, and $72^{\circ} \mathrm{C}$ for $7 \mathrm{~min}$.

Detection of the expression of ATM and PUMA at mRNA level: qRT-PCR was performed using a kit. Primers used in PCR reaction were: 5'-ATCTGCCGTCAACTAGAA-3' (upstream) and 5'-GATCTCGAATCAGGCGCTTAAA-3' (downstream) for ATM; 5'-GCCAGATTTGTGAGACAAG AGG-3' (upstream) and 5'-CAGGCACCTAATTGGGCTC-3' (downstream) for PUMA. $\beta$-actin was used as endogenous control. Data were processed using $2^{-\Delta \Delta \mathrm{Ct}}$ method.

Observation indicators. Expression of ATM and PUMA in colorectal cancer tissues, adjacent noncancerous tissues and normal colorectal tissues were compared; correlations between expression of ATM mRNA in colorectal cancer tissues and clinicopathological features were analyzed.

Statistical analysis. Data were analyzed using SPSS 22.0 software (IBM Corp., Armonk, NY, USA). Countable data are
Table I. Expression of ATM mRNA in different tissues (mean \pm standard deviation).

\begin{tabular}{lccc}
\hline ATM & $\begin{array}{c}\text { Colorectal } \\
\text { cancer tissue }\end{array}$ & $\begin{array}{c}\text { Adjacent } \\
\text { noncancerous } \\
\text { tissue }\end{array}$ & $\begin{array}{c}\text { Normal } \\
\text { mucosa tissue }\end{array}$ \\
\hline ATM mRNA & $5.63 \pm 0.02$ & $2.47 \pm 0.06^{\mathrm{a}}$ & $2.31 \pm 0.04^{\mathrm{a}}$ \\
t-value & & 4.534 & \\
P-value & & 0.07 & \\
\hline
\end{tabular}

${ }^{a} \mathrm{P}<0.05$ compared with colorectal cancer tissues. ATM, ataxiatelangiectasia mutated.

expressed as rate (n\%), and comparison between groups were performed using $\chi^{2}$ test. Measurement data were expressed as mean \pm standard deviation, and comparisons between groups were performed by $\mathrm{t}$-test. $\mathrm{P}<0.05$ was considered to indicate a statistically significant difference.

\section{Results}

Expression of ATM mRNA in colorectal cancer tissues, adjacent noncancerous tissue and normal colorectal tissues. Expression level of ATM in colorectal cancer tissues was significantly higher than that in normal mucosa and adjacent noncancerous tissues $(\mathrm{P} \leq 0.05)$ at mRNA level. However, there was no significant difference in ATM mRNA expression between normal mucosa tissue and adjacent noncancerous tissue $(\mathrm{P}=0.07)$ (Table I).

Expression of ATM mRNA in colorectal cancer and the correlation with clinicopathological features. Expression level of ATM mRNA was negatively correlated with the degree of colorectal cancer differentiation ( $\mathrm{r}=-0.312, \mathrm{P}=0.013)$; expression of ATM mRNA in colorectal cancer tissues was not correlated with age, sex, depth of tumor invasion, lymph node metastasis or clinical stage $(\mathrm{P}>0.05)$ (Table II).

Expression of PUMA mRNA in colorectal cancer tissues, adjacent noncancerous tissues and normal colorectal tissues. Expression levels of PUMA mRNA in colorectal cancer tissues, adjacent noncancerous tissues and normal colorectal tissues were $0.68 \pm 0.07,0.88 \pm 0.04$ and $1.76 \pm 0.06$, respectively. Expression level of PUMA mRNA in colorectal cancer tissues and adjacent noncancerous tissues was significantly lower than that in normal colorectal tissues $(\mathrm{P}<0.05)$ (Table III).

\section{Discussion}

Colorectal cancer is the third most common cancer in the world and is a leading cause of cancer-related death. Surgery is the primary treatment of patients with early stage of colorectal cancer. However, most patients are diagnosed with advanced stages and distant metastasis is also very common. Drug treatment is challenged by drug resistance and high recurrence rate. At molecular level, colorectal cancer is a heterogeneous disease, and approximately $30 \%$ of cases are caused by genetic factors. 
Table II. Correlation between expression level of ATM mRNA and clinicopathological features.

\begin{tabular}{lcccc}
\hline Characteristics & Cases & ATM mRNA & t-value & P-value \\
\hline Sex & & & & 0.270 \\
$\quad$ Male & 33 & $4.32 \pm 0.07$ & 2.396 & \\
$\quad$ Female & 34 & $3.94 \pm 0.02$ & & \\
Age (years) & & & & 0.394 \\
$\leq 60$ & 30 & $3.99 \pm 0.03$ & 4.279 & \\
$>60$ & 37 & $4.52 \pm 0.08$ & & \\
Pathological stage & & & & 0.081 \\
T1-T2 stage & 34 & $5.29 \pm 0.01$ & 3.385 & \\
$\quad$ T3-T4 stage & 33 & $4.96 \pm 0.05$ & & \\
Differentiation degree & & & & 0.013 \\
$\quad$ High & 36 & $3.35 \pm 0.06$ & 5.391 & \\
Low & 31 & $5.63 \pm 0.02$ & & \\
Tumor infiltration & & & & 0.199 \\
$\quad$ Mucosal and muscular & 38 & $5.29 \pm 0.07$ & 4.263 & \\
$\quad$ Outer layer & 29 & $5.54 \pm 0.09$ & & \\
Lymph node metastasis & & & & 0.067 \\
$\quad$ Yes & 35 & $4.48 \pm 0.05$ & 2.738 & \\
$\quad$ No & 32 & $4.37 \pm 0.02$ & & \\
\hline
\end{tabular}

ATM, ataxia-telangiectasia mutated.

In the development of colorectal adenocarcinoma, deletions or mutations of a specific proto-oncogene or tumor suppressor gene in epithelial cells of gastrointestinal tract cause the onset, progression and metastasis of colorectal cancer. Studies on mutations of cancer-related gene can provide valuable information for the treatment and prognosis (4). Ataxia-telangiectasia mutated (ATM) is newly discovered gene that can initiate the repair of DNA double-strand breaks, and the expression level of ATM is closely correlated with the repair of damaged cells and the regulation of apoptosis cycle (5). Studies have shown that (6-8) abnormal expression of ATM plays pivotal roles in the occurrence of lung cancer, breast cancer, thyroid cancer and other types of cancers by regulating gene expression and angiogenesis. In addition, abnormal cell apoptosis is also a cause of the development and progression of tumor. The p53 upregulated modulator of apoptosis (PUMA) is a newly discovered pro-apoptotic gene. As a member of Bcl-2 family, PUMA can induce apoptosis through mitochondrial pathway (9). Some studies have shown that (10-12), expression of PUMA protein is closely correlated with the onset, lymph node metastasis and prognosis of liver cancer, gastric cancer and renal cell cancer.

In this study, expression of ATM and PUMA in patients with colorectal cancer was detected by qRT-PCR to explore the roles of the two genes in the development and progression of colorectal cancer. We found that, expression level of ATM was significantly higher in colorectal cancer than in normal mucosa tissues and adjacent noncancerous tissues $(\mathrm{P} \leq 0.05)$. While expression level of ATM in normal mucosa tissues was
Table III. Expression of PUMA mRNA in different tissue $($ mean $\pm \mathrm{SD})$.

\begin{tabular}{lccc}
\hline PUMA & $\begin{array}{c}\text { Colorectal } \\
\text { cancer tissue }\end{array}$ & $\begin{array}{c}\text { Adjacent } \\
\text { noncancerous } \\
\text { tissue }\end{array}$ & $\begin{array}{c}\text { Normal } \\
\text { colorectal } \\
\text { tissue }\end{array}$ \\
\hline PUMA mRNA & $0.68 \pm 0.07$ & $0.88 \pm 0.04$ & $1.76 \pm 0.06$ \\
t-value & & 1.629 & 2.011 \\
P-value & & 0.009 & 0.043 \\
\hline
\end{tabular}

PUMA, p53 upregulated modulator of apoptosis.

not significantly different from that in adjacent noncancerous tissues $(\mathrm{P}=0.07)$. In addition, expression of ATM at mRNA level was negatively correlated with the degree of colorectal cancer differentiation $(\mathrm{r}=-0.312, \mathrm{P}=0.013)$, while expression of ATM mRNA in colorectal cancer tissues was not significantly correlated with age, sex, depth of tumor invasion, lymph node metastasis and clinical stage $(\mathrm{P}>0.05)$. Based on these results, we hypothesized that, as a DNA damage response gene, expression level of ATM can be upregulated after cancer cell damage caused by chemical drugs or radiation to initiate a self-repair mechanism or induce apoptosis of damaged cells, so as to promote the renewal of cancer cells and maintain the activity of tumor cells. This finding is consistent with previous studies that ATM-deficient cancer cells have high sensitivity to radiotherapy and chemotherapy $(13,14)$.

In this study, we also found that expression levels of PUMA in colorectal cancer tissues, adjacent noncancerous tissues and normal mucosa tissues were $0.68 \pm 0.07,0.88 \pm 0.04$ and $1.76 \pm 0.06$, respectively. Expression level of PUMA in colorectal cancer tissues and adjacent noncancerous tissues was lower than that in normal mucosa tissues. In addition, PUMA expression is negatively correlated with tumorigenesis $(r=-0.312, P=0.013)$, which is consistent with previous studies (15). Apoptosis disorders play key roles in tumorigenesis and anticancer treatment. The reduced expression level of PUMA in cancer cells indicates its pro-apoptotic functions. Studies have shown that some drugs can increase the sensitivity of tumor cells to chemotherapy by upregulating the expression level of PUMA in cancer cells $(16,17)$.

Recent studies found that the occurrence of mutations in ATM gene may be related to its phosphorylation and methylation, and the activated IL- 8 by oxidative stress $(18,19)$. Studies also reported that caffeine can inhibit apoptosis of cancer cells by inhibiting the activation of ATM-Chk2p53-PUMA channel (20), indicating that ATM and PUMA may act on different sites of the same channel. This study is limited by the small sample size. The interactions between the two genes were not studied. Thus, further studies are still needed.

In conclusion, ATM mRNA was abnormally expressed in colorectal cancer tissue. PUMA gene expression in colorectal cancer tissue was downregulated, and is negatively correlated with the occurrence of cancer. With in-depth studies, the two genes may potentially be targets for the treatment of colorectal cancer. 


\section{References}

1. Smolle MA, Pichler M, Haybaeck J and Gerger A: Genetic markers of recurrence in colorectal cancer. Pharmacogenomics 16: 1315-1328, 2015.

2. Lu Y, Gao J and Lu Y: Downregulated Ku70 and ATM associated to poor prognosis in colorectal cancer among Chinese patients. Onco Targets Ther 7: 1955-1961, 2014.

3. Xu K, Chen G, Qiu Y, Yuan Z, Li H, Yuan X, Sun J, Xu J, Liang X and Yin P: miR-503-5p confers drug resistance by targeting PUMA in colorectal carcinoma. Oncotarget 8: 21719-21732, 2017.

4. De Rosa M, Pace U, Rega D, Costabile V, Duraturo F, Izzo P and Delrio P: Genetics, diagnosis and management of colorectal cancer (Review). Oncol Rep 34: 1087-1096, 2015.

5. Hu F, Liu C, Liu H, Xie L and Yu L: Ataxia-telangiectasia mutated (ATM) protein signaling participates in development of pulmonary arterial hypertension in rats. Med Sci Monit 23 . 4391-4400, 2017.

6. Beumer JH, Fu KY, Anyang BN, Siegfried JM and Bakkenist CJ: Functional analyses of ATM, ATR and Fanconi anemia proteins in lung carcinoma : ATM, ATR and FA in lung carcinoma. BMC Cancer 15: 649, 2015.

7. Bhattacharya N, Mukherjee N, Singh RK, Sinha S, Alam N, Roy A, Roychoudhury S and Panda CK: Frequent alterations of MCPH1 and ATM are associated with primary breast carcinoma: Clinical and prognostic implications. Ann Surg Oncol 20 (Suppl 3): S424-S432, 2013.

8. Hu JL, Hu SS, Hou XX, Zhu X, Cao J, Jiang LH and Ge MH: Abnormal expression of DNA double-strand breaks related genes, ATM and gammaH2AX, in thyroid carcinoma. Int J Endocrinol 2015: 136810, 2015.

9. Li Y, Guo Q, Liu X, Wang C and Song D: PUMA-mediated mitochondrial apoptotic disruption by hypoxic postconditioning. Apoptosis 20: 1026-1032, 2015.

10. Peng SL, Yao DB, Zhao Y, Xu F, Jia CJ, Xu YQ and Dai CL: Prognostic value of PUMA expression in patients with HBV-related hepatocellular carcinoma. Eur Rev Med Pharmacol Sci 19: 38-44, 2015.
11. Wen T, Hou K, Li Z, Li L, Yu H, Liu Y, Li Y and Yin Z: Silencing $\beta$-linked $\mathrm{N}$-acetylglucosamine transferase induces apoptosis in human gastric cancer cells through PUMA and caspase-3 pathways. Oncol Rep 34: 3140-3146, 2015.

12. Zhou X, Tolstov Y, Arslan A, Roth W, Grüllich C, Pahernik S, Hohenfellner $\mathrm{M}$ and Duensing S: Harnessing the p53-PUMA axis to overcome DNA damage resistance in renal cell carcinoma. Neoplasia 16: 1028-1035, 2014.

13. Teng PN, Bateman NW, Darcy KM, Hamilton CA, Maxwell GL, Bakkenist CJ and Conrads TP: Pharmacologic inhibition of ATR and ATM offers clinically important distinctions to enhancing platinum or radiation response in ovarian, endometrial, and cervical cancer cells. Gynecol Oncol 136: 554-561, 2015.

14. Zhang Z, Wang CZ, Du GJ, Qi LW, Calway T, He TC, Du W and Yuan CS: Genistein induces $\mathrm{G} 2 / \mathrm{M}$ cell cycle arrest and apoptosis via ATM/p53-dependent pathway in human colon cancer cells. Int J Oncol 43: 289-296, 2013.

15. Hua Y, Hu Q, Piao Y, Tang Q and Feng J: Effect of capilliposide for induction apoptosis in human nasopharyngeal cancer CNE-2 cells through up-regulating PUMA expression. J Cancer Res Ther 11 (Suppl): C239-C243, 2015.

16. Chen D, Wei L, Yu J and Zhang L: Regorafenib inhibits colorectal tumor growth through PUMA-mediated apoptosis. Clin Cancer Res 20: 3472-3484, 2014

17. Wang H, Zhang L, Yang X, Jin Y, Pei S, Zhang D, Zhang H, Zhou B, Zhang Y and Lin D: PUMA mediates the combinational therapy of 5-FU and NVP-BEZ235 in colon cancer. Oncotarget 6: 14385-14398, 2015.

18. Mehdipour P, Karami F, Javan F and Mehrazin M: Linking ATM promoter methylation to cell cycle protein expression in brain tumor patients: Cellular molecular triangle correlation in ATM territory. Mol Neurobiol 52: 293-302, 2015.

19. Chen WT, Ebelt ND, Stracker TH, Xhemalce B, Van Den Berg CL and Miller KM: ATM regulation of IL-8 links oxidative stress to cancer cell migration and invasion. eLife 4: 4, 2015.

20. Zhang ZW, Xiao J, Luo W, Wang BH and Chen JM: Caffeine suppresses apoptosis of bladder cancer RT4 cells in response to ionizing radiation by inhibiting ataxia telangiectasia mutated-Chk2-p53 axis. Chin Med J (Engl) 128: 2938-2945, 2015. 